TNF $\alpha$ synthesis (in adipose and synovial tissues). The level of adiponectin was high in both adipose tissues and stayed unaffected by tested cytokines. Interestingly, the concentration of this adipokine was higher in AA and SM obtained from OA than from RA patients. AA and SM explants spontaneously secreted leptin, but the production of this adipokine did not change upon treatment. Leptin produced by subcutaneous tissue appeared only in the presence of cytokines (TNF $\alpha$, IL15 and IL17).

Conclusions Both AA and ScA tissues spontaneously secreted a large amount of IL6, IL8 and adiponectin (1-5 ng/ $\mathrm{ml})$. Cytokines (TNF $\alpha$ IFN $\gamma$ ) raised IL6 and IL8 secretion but had no effect on adiponectin release. Secretory activities of adipose tissues differed because, upon cytokine treatment, AA tissue was a richer source of IL6 and released leptin spontaneously, while ScA secreted this adipokine only upon cytokine treatment. Our results therefore give direct evidence that, in $\mathrm{RA}$, adipose tissue is an active participant of the cytokine network.

\title{
A134 RHEUMATOID ADIPOSE TISSUE IS A POTENT SOURCE OF CYTOKINES
}

M Jastrzebska, E Kontny, I Janicka, W Maslinski, P Maldyk Institute of Rheumatology, Warsaw, Poland

\subsection{6/ard.2010.129643k}

Objectives Numerous cytokines and adipokines have a fundamental role in synovial inflammation and articular destruction characteristic of rheumatoid arthritis (RA). Cytokines are thought to originate from inflamed synovial tissue. Recently, adipose tissue has been suggested to play a role in chronic inflammatory joint diseases, but its ability to synthesise proinflammatory cytokines has not been well characterised. The aim of the present work was to investigate whether rheumatoid articular adipose tissue secretes cytokines and adipokines relevant to RA pathogenesis.

Materials and Methods Articular (AA) and subcutaneous (ScA) adipose tissue and synovial membrane (SM) explants obtained from patients with RA who were undergoing knee joint replacement surgery were cultured $(100 \mathrm{mg} / \mathrm{ml})$ for $18 \mathrm{~h}$ in medium (DMEM) alone or in the presence of lipopolysaccharide (LPS) $(1 \mu \mathrm{g} / \mathrm{ml})$ or cytokines: tumour necrosis factor (TNF) $\alpha$, interferon (IFN) $\gamma$, interleukin (IL)15, IL17 or IL23 $(10$ and $40 \mathrm{ng} / \mathrm{ml})$. Concentrations of TNF , IL6, IL8, adiponectin and leptin were measured in culture supernatants by ELISA.

Results Untreated cells spontaneously produced high levels of IL6 and IL8. IL6 further raised upon LPS and TNF $\alpha(A A)$ or only LPS (ScA) treatment. After TNF $\alpha$ and IFN $\gamma$ stimulation, AA secreted more IL6 than ScA. LPS, TNF $\alpha$ and IFN $\gamma$ significantly increased IL8 secretion. The level of this cytokine was similar in AA and ScA. Spontaneous secretion of TNF $\alpha$ was negligible, while LPS (but not cytokines) triggered marked 